\title{
Cooperation Learning of Flip teaching style on the MBA Mathematics Education Efficiency
}

\author{
Yi-Bin Li \\ College of Business Administration, Huaqiao University, Quanzhou 362021, CHINA \\ Business Management Research Center, Huaqiao University, Quanzhou 362021, CHINA \\ East Business Management Research Center, Huaqiao University, Quanzhou, CHINA \\ Wen-Zhi Zheng \\ College of Business Administration, Huaqiao University, Quanzhou 362021, CHINA \\ Business Management Research Center, Huaqiao University, Quanzhou 362021, CHINA \\ East Business Management Research Center, Huaqiao University, Quanzhou, CHINA \\ Fan Yang \\ Key Laboratory of Urban Environment and Health, Institute of Urban Environment, Chinese Academy of Sciences, Xiamen \\ 361021, CHINA \\ University of Chinese Academy of Sciences, Beijing 100049, CHINA
}

Received 26 May 2017 • Revised 18 July 2017 • Accepted 6 September 2017

\begin{abstract}
This study aims to discuss the effects of flipped teaching supported cooperative learning on MBA students' learning achievement, attitudes toward technology, cooperative learning attitudes, and course satisfaction in the mathematics and science education. By applying quasi-experimental research, $120 \mathrm{MBA}$ students of a national university in China are selected as the research objects. Two classes are randomly sampled for a class as the experiment group $(N=75)$ and the other class as the control group $(N=45)$. The students in the experiment group apply flipped teaching supported cooperative learning, while those in the control group adopt traditional didactic cooperative learning. Both the experiment group and the control group are paired with heterogeneous cognitive styles for the 4-week (16 sessions) teaching experiment. The research results reveal that the flipped teaching supported cooperative learning could actually enhance students' learning achievement, course satisfaction, and cooperative learning attitudes in the science education. However, there is no significant effect between learning achievement, course satisfaction and cooperative learning attitudes. On the other hand, web-based learning selfefficacy would influence students' learning achievement and course satisfaction in the mathematics and science education.
\end{abstract}

Keywords: flipped teaching, science education, learning achievement, course satisfaction

\section{INTRODUCTION}

Group teaching, as the most traditional and common teaching model currently, focuses on one-way instruction of a teacher. Under such teaching environment, students often lack for actively thinking of lesson contents and have to synchronously accept knowledge in the classroom. A teacher therefore could not take care of students with various levels to result in student differences in absorption and comprehension. Some students even consider that

(C) Authors. Terms and conditions of Creative Commons Attribution 4.0 International (CC BY 4.0) apply. Correspondence: Fan Yang, Key Laboratory of Urban Environment and Health, Institute of Urban Environment, Chinese Academy of Sciences, Xiamen 361021, China. 


\section{Contribution of this paper to the literature}

- To change such a dilemma, common lesson preparation among teachers might be an effective method. Having teachers with the same subject discuss with each other and mutually support and record the teaching films could largely reduce the time for lesson preparation.

- To have students actually watch films on the teaching platform before the course, teachers have to think of the reward and confirmation mechanism, e.g. answering questions after watching teaching films or writing opinions on the teaching platform, to effectively achieve flipped teaching.

- The application of flipped teaching supported cooperative learning in this study allows students watching teaching films on the teaching platform before the course and then preceding cooperative learning in the classroom.

they have learned concepts in the course but find out that they do not really comprehend such concepts when doing assignments at home. Unfortunately, they have nobody to immediately provide assistance. When dividing learning processes into "delivery of knowledge" and "absorption and internalization of knowledge", group teaching simply stresses on the delivery of knowledge but ignores the knowledge absorption and internalization of students. To improve group teaching, flipped classroom, a teaching model proposed recently, has been popular in the education circle. The concept refers to flipping over the traditional teaching process of "lecturing in class, doing assignments at home". Students have to complete the knowledge learning before the class and precede cooperative learning with teachers and classmates in the school (Jensen, Kummer \& Godoy, 2015; O'Flaherty \& Phillips, 2015). A classroom therefore becomes the place for the interaction between teachers and students as well as among students. Different from traditional teaching models, a flipped classroom allows students selecting adaptive and individualized education, according to personal preference, to acquire knowledge through self-learning and enhancing the learning interests through the cooperative learning among classmates in the classroom to enhance the knowledge absorption and internalization (Baker, 2000; Wong, Ip, Lopes \& Rajagopalan, 2014). The cooperation among students not only improves the passive learning in traditional group teaching but also promotes students' thinking ability to enhance the learning interests (Chu, Hwang, Tsai, \& Tseng, 2010).

A flipped classroom is based on constructivism and social-learning theory (Moraros, Islam, Yu, Banow \& Schindelka, 2015) as it allows and encourages students regarding learning as an activity and the process of socialization to construct knowledge through self-learning before the course and in-depth discussion in the classroom. In terms of social-learning theory, self-efficacy is a primary factor in learning. Bandura (1997) regarded self-efficacy as individual belief in being able to complete specific tasks. Besides, self-efficacy could affect the intensity of individual belief to cause specific results that a learner had to analyze and reflect the learning tasks, judge the balance between the ability and the learning objectives, and further self-evaluate the requirement for achieving the objectives (Shea \& Bidjerano, 2010). Teachers, in a flipped classroom, used to provide materials like textbooks, traditional handouts, or audio presentation (PPT) for students' watching or learning to complete the course preparation before the class (Wu and Tai, 2016). However, the prevalence of online e-teaching, particularly the assistance of MOOCs, has a flipped classroom develop into the new trend of digital learning. With changing information technology, multimedia digital teaching is constantly impacting original teaching styles; multiple knowledge are presented through texts, pictures, and clear audio with sound and light effects; and, even learning environments and learning materials are simulated to induce students' learning interests and enhance the teaching effect (Wu and Tai, 2016). Flipped teaching could be regarded as a transformation of mixed teaching model, but online e-teaching and classroom teaching covered in the mixed teaching model are practiced based on traditional teaching orders. Flipped teaching practices actual teaching activity, with online e-teaching, before classroom teaching which then does not focus on teaching but on common discussion, problem solving, or guiding further thinking. Although flipped teaching simply "flips over" the teaching order, the core value is to give the learning initiative to students that a teacher's role or task in classroom teaching is not to teach, but to discuss or dialogue with students (Kong, 2014). 


\section{Research Focus}

The content of science education lies in the cultivation of scientific concepts. The science deduction process allows deducing and understanding the development process of new technology and actually researching and developing scientific products in the course to cultivate specific R\&D experiences. Since the science education in higher education stresses more on life-related mathematics \& science, science \& technology innovation, and the sustainable operation of energy saving and environmental protection, MBA mathematics \& science teaching emphasizes on cultivating students' "thinking" ability. Moreover, the design of MBA course outline definitely indicates that problem solving is the key design of mathematics \& science teaching and the processes of logic, practice, and application are emphasized. Especially, most MBA students, with in-service education, join in the course to learn new knowledge and skills that the requirements for learning mathematics \& science does not simply "do wonderfully", but "solve skillfully" to actually solve the tasks and problems assigned by the teachers. Nevertheless, such a learning process can hardly be reached in other courses that it is the specialty of the mathematics \& science course. To cultivate students' future competitiveness, it is necessary to have students effectively learn professional knowledge and skills through efficient learning and to think of new teaching approaches and strategies (Zakaria, Chin, \& Daud, 2010). For this reason, well applying the mathematics \& science course matched with the guidance of perfectly designed materials and the flipped teaching strategy would effectively develop students' multiple abilities and promote the technology learning interests. This study intends to enhance MBA students' learning outcome in the mathematics \& science course with flipped teaching supported cooperative learning by effectively applying the teaching films recorded by the teacher before the class and combining the function of web-based teaching platform in e-class for the 4-week (12 sessions) teaching experiment to further understand the effects of flipped teaching on MBA students' learning achievement, attitudes toward technology, cooperative learning attitudes, and course satisfaction in the mathematics \& science course. Specifically speaking, this study intends to discuss 1.the effects of different teaching strategies on learning achievement, cooperative learning attitudes, and course satisfaction in mathematics and science education, 2.the effects of learning participation in flipped teaching supported cooperative learning on learning achievement, cooperative learning attitudes, and course satisfaction in mathematics and science education, and 3.the effects of web-based learning self-efficacy in flipped teaching supported cooperative learning on learning achievement, cooperative learning attitudes, and course satisfaction in mathematics and science education.

\section{LITERATURE REVIEW}

\section{Flipped Teaching}

Flipped teaching is not a new idea, but the development of digital technology allows students ubiquitously receiving information and contacting with peers so that flipped teaching is re-emphasized. In the digital era, flipped teaching contains mixed learning design that digital technology has the passively delivered learning knowledge exceed formal curricula, while students in formal curricula more actively construct learning concepts through active learning (Davies et al., 2013; Flumerfelt \& Green, 2013). Students in flipped teaching are positioned as being able to control the learning speed and schedule and establish individually required learning steps. Teachers in flipped teaching could achieve meaningful learning, without restrictions, through observation, guidance, comments, and assistance (Flumerfelt \& Green, 2013).

After the popularity of computer, network, and cloud technologies, classrooms are no longer the sole field for "teaching" and "learning". Flipped teaching presents distinct perceived learning effect of students, but students generally show positive reaction to flipped teaching. Students favor watching teaching videos by themselves, but prefer interactive learning activities in classrooms (Wong et al., 2014; Moraros et al., 2015). Day and Foley (2006) discovered that, under same topics, assignments, and time, students in the experiment group who watched films outside the classroom but participated in interactive learning in the classroom outperformed the control group on the assignments, projects, and examinations. Kong (2014) discovered that flipped teaching could significantly promote students' information literacy and critical thinking ability. Besides, teachers and students had more team discussion time to enhance the students' information sharing and peer discussion before and after the classroom 
learning activity. Several studies indicated that flipped teaching could enhance students' learning outcome and provide more team discussion time to enhance the development of multiple abilities. Nonetheless, most research was preceded in universities, but seldom applied to MBA education. Moreover, it was mostly applied to general courses, but seldom to mathematics \& science education. For this reason, this study intends to promote MBA students' learning outcome in mathematics \& science education by utilizing flipped teaching supported cooperative learning.

\section{Learning Participation}

Participation is a part of learning (Wenger, 1998). Past research pointed out participation as individual voluntary actions and the invested resources and commitment in the process. The degree of participation is the observable degree of involvement and the invested efforts in the process. Internet-based learning environment allows teaching not being restricted to space and time that students could learn at any places and flexibly arrange the learning time to really achieve the situation of learning anytime and classrooms everywhere (Chu et al., 2010). In addition to not being restricted to time and space, Internet-based learning could automatically record students' learning activities on the web-based learning platform to the system. Moreover, teachers could understand students' learning conditions and performance through the learning participation records. Flipped teaching stresses on practicing actual teaching activity, through online e-teaching, before the classroom teaching. Students' degree of online participation therefore becomes primary. The time of students logging in the web-based teaching platform for reading materials is applied to evaluate the learning participation.

\section{Self-Efficacy}

Individual self-efficacy refers to individual belief, under special situations, in evaluating the ability to complete specific objectives and tasks. Such a belief is the ability judgment of a person completing certain behaviors that it would influence the person's ideas and actions, the efforts and persistence in encountering problems or obstacles, and the selection of tasks and the performance (Bandura, 1997; Wang, Shannon \& Ross, 2013). Internetbased learning (IBL) self-efficacy describes individuals being confident and believing that they are capable of mastering the online course or web-based learning activity (Yukselturk \& Bulut, 2007; Chu et al., 2010). According to IBL self-efficacy, Cheng and Tsai (2011) proposed web-based learning self-efficacy (WLSE), which referred to students' opinions and self-confidence in being able to complete online courses and participating in and completing online courses with the Internet and computer skills. With the use of digital technology, flipped teaching has the passively delivered learning knowledge exceed formal curricula. In this case, web-based learning self-efficacy might be a key success factor in flipped teaching.

\section{METHODOLOGY OF RESEARCH}

\section{Research Model Development}

Quasi-experimental research is applied in this study to discuss the effects of applying flipped teaching supported cooperative learning and traditional didactic cooperative learning to mathematics and science education on learning achievement, attitudes toward technology, cooperative learning attitudes, and course satisfaction. The research structure in this study is shown as Figure 1. 


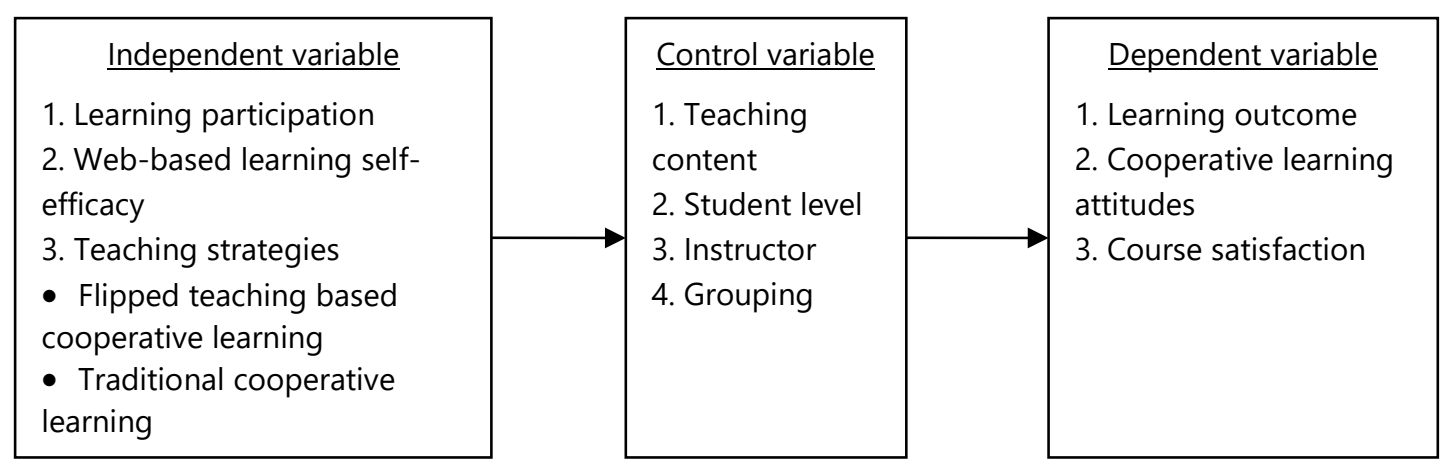

Figure 1. Research model

\section{Independent variable}

Learning participation: Learning participation in this study calculates the total time of the experiment group from the teaching experiment to the material reading on the Internet-based teaching platform. Web-based learning self-efficacy: Web-based learning self-efficacy in this study refers to students' test score of the web-based learning self-efficacy scale. The scale refers to Cheng and Tsai (2011), and the Cronbach's a appears 0.93. Teaching strategy: According to the teaching strategy, students in this study are divided into the experiment group (EG) with "flipped teaching supported cooperative learning" and the control group (CG) with "traditional didactic cooperative learning".

\section{Control variable}

Teaching content: Based on current MOOCs platform, the teacher designs 5-unit mathematics and science courses and records relevant teaching films before the course on the web-based teaching platform. Both the experiment group and the control group use the same teaching films. Student level: MBA students of a national university in China are selected as the research objects, who have studied basic mathematics before, for the teaching experiment. The student level therefore does not appear large differences. Instructor: Both the experiment group and the control group has the same instructor, who graduated from a graduate school of mathematics in a famous university in China and has 12-year teaching experiences in MBA mathematics and science education. Grouping: Heterogeneous grouping is applied to this study. All participants precede the cognitive style scale before the experiment. Based on the pretest scores, top 50\% students are in the high-score group, and the rest are in the lowscore group. A cooperative learning team is separately selected from the high-score group and the low-score group, which are paired by heterogeneous grouping with cognitive styles.

\section{Dependent variable}

Course learning achievement: The course learning achievement in this study refers to students' evaluation performance after the course. Cooperative learning attitudes: The cooperative learning attitudes in this study refers to students' test scores on the cooperative learning attitude scale. The scale refers to Nam and Zellner (2011), and the Cronbach's a is 0.93. Course satisfaction: It refers to students' scores on the course satisfaction scale, which is referred to Frey, Faul and Yankelov (2003) and shows the Cronbach's a 0.97.

\section{Participants of Research}

Two classes of (120) MBA students of a national university in China who are studying "Statistical mathematics" are selected as the research objects in this study. With random grouping, a class is set as the experiment group (75 students) and the other class is the control group (45 students). Students in the experiment group apply flipped teaching supported cooperative learning, and those in the control group adopt traditional didactic cooperative learning. 
Table 1. Analysis of Variance of cooperative learning attitudes under the teaching strategy

\begin{tabular}{lccccccc}
\hline & $\begin{array}{c}\text { Teaching } \\
\text { strategy } \\
\text { group }\end{array}$ & $\begin{array}{c}\text { No. of } \\
\text { people }\end{array}$ & M & SD & $\begin{array}{c}\text { Adjusted } \\
\text { Mean }\end{array}$ & F & $\boldsymbol{p}$ \\
\hline $\begin{array}{l}\text { Cooperative learning } \\
\text { attitudes }\end{array}$ & EG & 75 & 61.12 & 5.33 & 60.97 & 8.287 & .01 \\
\hline
\end{tabular}

\section{Procedures}

Three sessions (3hrs) before the formal course are used for the course explanation and the brief introduction of the web-based teaching platform as well as for completing the pretests of cognitive style scale, webbased learning self-efficacy scale, attitudes toward technology scale, and cooperative learning attitude scale. Based on the cognitive style scale, the students are paired with heterogeneous grouping. Since most students have not used the mathematics and science education platform, the teacher, using 6 sessions in a week, has all students understand the basic use of the mathematics platform. Furthermore, all students learn to operate the evaluation through assignments. In the following 4 weeks (16 sessions), students in the experiment group have to watch the teaching films assigned by the teacher before the class. To effectively control the students completing the films before the class, the teacher request the students to answer 1 3 questions on the web-based teaching platform after watching the films. In the classroom, the teacher simply solves problems, but not lecturing, and the students precede group discussion and complete the assignments. Students in the control group, in the classroom, are lectured the teaching films on the web-based teaching platform by the teacher and then answer the same questions as those for the experiment group on the web-based teaching platform. The students further precede group discussion and complete the assignments. After completing the assignments, the teacher collects qualitative data with open-ended questionnaire aiming at the assignment contents and the technology practice. When all courses are completed, the last session is utilized for the course satisfaction and cooperative learning attitude scales.

\section{RESULTS OF RESEARCH}

\section{Effects of Different Teaching Strategies on Mathematics and Science Education}

Independent-sample $t$ Test is used for testing the learning achievement in mathematics and science education between the control group and the experiment group. The analyses find out the mean assignments score 83.792 of the experiment group and 77.875 of the control group as well as the t-test result $-4.900(p<.001)$ with significant differences. It reveals that the assignment evaluation of students in the experiment group outperforms those in the control group. Accordingly, the application of flipped teaching supported cooperative learning could indeed enhance students' learning achievement in mathematics and science education. It also discovers that the mean course satisfaction score of students in the experiment group appears 103.417, but 91.691 in the control group, and the t-test result shows $-4.855(p<.001)$ with significant differences. It presents that students in the experiment group outperform those in the control group on course satisfaction. Accordingly, applying flipped teaching supported cooperative learning could actually promote students' course satisfaction. In this study, the cooperative learning attitude pretest score is the covariance, the teaching strategy grouping is the independent variable, and the cooperative learning attitude posttest score is the dependent variable for the in-group regression coefficient homogeneity test. The homogeneity test $p$ of the teaching strategy grouping and the cooperative learning attitude pretest does not achieve the significance that One-factor Analysis of Covariance (ANCOVA) could be continuously preceded. After excluding the effect of the cooperative learning attitude pretest, the cooperative learning attitudes of students in the experiment group is remarkably higher than those in the control group $(\mathrm{F}=6.858$ and $p<.01)$. Apparently, flipped teaching supported cooperative learning could notably promote students' cooperative learning attitudes (see Table 1). 
Table 2. Analysis of course satisfaction under web-based learning self-efficacy

\begin{tabular}{|c|c|c|c|c|c|c|c|}
\hline & $\begin{array}{c}\text { Teaching } \\
\text { strategy group }\end{array}$ & $\begin{array}{l}\text { No. of } \\
\text { people }\end{array}$ & M & SD & $\mathbf{F}$ & $\boldsymbol{p}$ & Post hoc \\
\hline \multirow{3}{*}{ Course satisfaction } & High & 25 & 115.23 & 12.52 & \multirow{3}{*}{30.701} & \multirow{3}{*}{$<.001$} & High > \\
\hline & Medium & 25 & 104.97 & 11.46 & & & Medium \\
\hline & Low & 25 & 99.52 & 11.71 & & & High > Low \\
\hline
\end{tabular}

Table 3. Analysis of Variance of cooperative learning attitudes under learning participation

\begin{tabular}{|c|c|c|c|c|c|c|c|}
\hline & $\begin{array}{c}\text { Teaching } \\
\text { strategy group }\end{array}$ & $\begin{array}{l}\text { No. of } \\
\text { people }\end{array}$ & M & SD & $\begin{array}{c}\text { Adjusted } \\
\text { Mean }\end{array}$ & $\mathbf{F}$ & $p$ \\
\hline \multirow{3}{*}{$\begin{array}{l}\text { Cooperative learning } \\
\text { attitudes }\end{array}$} & High & 25 & 59.41 & 6.58 & 58.97 & \multirow{3}{*}{0.579} & \multirow{3}{*}{.687} \\
\hline & Medium & 25 & 58.77 & 7.87 & 58.33 & & \\
\hline & Low & 25 & 58.13 & 8.15 & 59.49 & & \\
\hline
\end{tabular}

\section{Effects of Learning Participation on Mathematics and Science Education}

This study intends to understand the effects of learning participation in flipped teaching supported cooperative learning on learning achievement in cooperative learning attitudes and course satisfaction in mathematics and science education. According to the learning time on the web-based teaching platform, 75 students in the experiment group are divided into high-learning participation (top $1 / 3$ of total learning time), medium-learning participation (middle $1 / 3$ of total learning time), and low-learning participation (last $1 / 3$ of total learning time) for the test of homogeneity of variance. When it does not reach the significance, it does not violate the assumption of homogeneity of variance that One-factor Analysis of Variance (ANOVA) could be further preceded. When One-factor ANOVA reaches the significant difference, a posteriori comparison is proceeded. The posteriori comparison analysis discovers that ones with high-learning participation outperform those with medium- and low-learning participation on course satisfaction $(\mathrm{F}=30.701$ and $p<.001)$. The research results show that learning participation in flipped teaching would remarkably affect satisfaction in mathematics and science education and watching online films at free time in advance could actually enhance learning satisfaction. Research also finds out no significant difference of learning participation in flipped teaching supported cooperative learning to cooperative learning attitudes ( $\mathrm{F}=0.579$ and $p>$.687) (see Tables 2 and 3 ).

\section{Effects of Web-Based Learning Self-Efficacy on Mathematics and Science Education}

According to the scores in the web-based learning self-efficacy scale, 75 students in the experiment group are divided into high, medium, and low self-efficacy groups for the analysis. The analysis results reveal notable differences of web-based learning self-efficacy in learning achievement in mathematics \& science education $(\mathrm{F}=8.167$ and $p<.001)$. The posteriori comparisons show that ones with high web-based learning self-efficacy remarkably outperform those with medium and low web-based learning self-efficacy on course satisfaction, and ones with high web-based learning self-efficacy notably outperform those with low web-based learning selfefficacy on course satisfaction. Apparently, web-based learning self-efficacy in flipped teaching would significantly influence learning achievement in mathematics and science education, and students with high web-based learning self-efficacy present better learning achievement than those with low web-based learning self-efficacy. Furthermore, it is also discovered that ones with high web-based learning self-efficacy outperform those with medium and low web-based learning self-efficacy on learning satisfaction $(\mathrm{F}=23.11$ and $p<.001)$. In other words, web-based learning self-efficacy in flipped teaching would notably affect students' course satisfaction. Web-based learning self-efficacy in flipped teaching supported cooperative learning does not appear significant difference in cooperative learning attitudes that distinct web-based learning self-efficacy would not affect cooperative learning attitudes (see Table 4). 
Table 4. Analysis of course satisfaction under web-based learning self-efficacy

\begin{tabular}{|c|c|c|c|c|c|c|c|}
\hline & $\begin{array}{c}\text { Teaching } \\
\text { strategies group }\end{array}$ & $\begin{array}{l}\text { No. of } \\
\text { people }\end{array}$ & M & SD & $\mathbf{F}$ & $\boldsymbol{p}$ & Post hoc \\
\hline \multirow{3}{*}{ Course satisfaction } & High & 25 & 117.15 & 8.78 & \multirow{3}{*}{23.11} & \multirow{3}{*}{$<.001$} & \multirow{3}{*}{$\begin{array}{c}\text { High }>\text { Medium } \\
\text { High }>\text { Low } \\
\text { Medium }>\text { Low }\end{array}$} \\
\hline & Medium & 25 & 105.87 & 10.14 & & & \\
\hline & Low & 25 & 101.18 & 10.52 & & & \\
\hline
\end{tabular}

\section{DISCUSSION}

Independent-sample t Test and One-factor Analysis of Covariance are utilized in this study. The analyses show that students in the experiment group with "flipped teaching supported cooperative learning" outperform those in the control group with "traditional didactic cooperative learning" on learning achievement, course satisfaction, and cooperative learning attitudes in mathematics and science education. From students' qualitative data, it is discovered that students watching teaching films in advance and proceeding team discussion in the classroom present deeper discussion of questions because of more discussion time. Besides, they could better experience the importance of team cooperation due to more interaction time. What is more, they have more time to think of technology knowledge, as they watch teaching films in advance, that the application of flipped teaching to mathematics and science education could indeed significantly promote learning achievement, course satisfaction, and cooperative learning attitudes. Such a research result corresponds to various studies. Flipped teaching contains the mixed learning design that the use of digital technology has the passively delivered learning knowledge exceed formal curricula and students in formal curricula more actively construct learning concepts through active learning (Davies et al., 2013; Flumerfelt \& Green, 2013). Flipped teaching provides students with adequate time for discussion and learning and assist students in more interaction with the companions (Chao et al., 2015). Students could control the learning speed and schedule and establish individually required learning steps. Teachers, on the other hand, could achieve the meaningful learning through observation, guidance, comments, and assistance, without any restrictions (Flumerfelt \& Green; Fulton, 2012).

The advance of technology enhances the effect and practicability of flipped classrooms, which present better learning effect than simulated basic training, could induce learning motivation, and take larger learning differences into account. Students present positive reaction to flipped teaching; they favor watching teaching videos on their own, but prefer interactive learning activities in the classroom. The teaching films established for flipped teaching could effectively have students appear learning motivation on the material. Besides, when students feel that the films are useful and easy to follow and could help them comprehend new materials, the learning achievement and satisfaction would be enhanced (Day \& Foley, 2006; Kay \& Kletskin, 2012; Wong et al., 2014; Wu \& Tai, 2016). Furthermore, the analysis results reveal that students with high-learning participation in the experiment group with "flipped teaching supported cooperative learning" outperform those with low-learning participation on learning achievement and course satisfaction in mathematics and science education. However, there is no significant difference in cooperative learning attitudes, possibly because students with high-learning participation often watch teaching films and have more understanding and comprehension of the course that they could quickly complete the assignments in the classroom discussion and present higher sense of achievement. The learning achievement and course satisfaction therefore remarkably outperform those with low-learning participation. The research results correspond to the notable effects of Internet-based learning records, e.g. "course use time" and "material reading time", on learners' learning outcome and learning technology (Prinsen, Volman, Terwel \& Van den Eeden, 2009). Students have the same time for cooperative learning and problem solving that cooperative learning attitudes are not influenced by learning participation.

Finally, students with high web-based learning self-efficacy outperform those with low web-based learning participation on learning achievement and course satisfaction in mathematics and science education, while cooperative learning attitudes do not appear significant differences. It is considered that students with high webbased learning self-efficacy present the opinions and self-confidence to complete online courses and are confident in participating and completing online courses with the Internet and computer skills. They therefore have better 
self-confidence and consider that they are capable of completing relevant assignments to show higher sense of achievement. As a result, the learning achievement and course satisfaction are obviously better than those with low web-based learning self-efficacy. This research result corresponds to that students with higher motivation on online courses would strengthen the self-efficacy and course satisfaction, and students with higher technology self-efficacy and course satisfaction would eventually show better performance (Wang et al., 2013). All students in this course would receive the same course contents and learn new science knowledge; besides, all students have same time for cooperative learning and problem solving in the course that cooperative learning attitudes would not be affected by web-based learning self-efficacy.

\section{CONCLUSIONS}

Flipped teaching is a popular teaching strategy currently; however, it takes a lot of time and manpower to have online materials or online films able to delivery course points. Such restrictions have current teachers focus on course data or instructional PPT collection, but not provide teaching films recorded aiming at the course. To change such a dilemma, common lesson preparation among teachers might be an effective method. Having teachers with the same subject discuss with each other and mutually support and record the teaching films could largely reduce the time for lesson preparation. Besides, to have students actually watch films on the teaching platform before the course, teachers have to think of the reward and confirmation mechanism, e.g. answering questions after watching teaching films or writing opinions on the teaching platform, to effectively achieve flipped teaching. What is more, although the Internet is popular, few students do not have fast Internet access at home to watch teaching films. Consequently, a teacher should understand all students' conditions before applying flipped teaching so as to smoothly precede the teaching activity. The application of flipped teaching supported cooperative learning in this study allows students watching teaching films on the teaching platform before the course and then preceding cooperative learning in the classroom. Future researchers could apply online cooperative learning to continuously discuss the relationship between flipped teaching and learning outcome.

\section{ACKNOWLEDGEMENT}

The authors are grateful to the valuable comments made by the reviewers. The authors are supported by the Education and Research Projects of Young and Middle-aged Teachers in Fujian Province (JAS160039).

\section{REFERENCES}

Baker, J. W. (2000). The "classroom flip": Using web course management tools to become the guide by the side. In J. A. Chambers (Ed.), Selected papers from the 11th International Conference on College Teaching and Learning (pp. 9-17). Jacksonville, FL: Florida Community College at Jacksonville.

Bandura, A. (1997). Self-efficacy: The exercise of control. New York: W. H. Freeman.

Betihavas, V., Bridgman, H., Kornhaber, R., \& Cross, M. (2016). The evidence for 'flipping out': a systematic review of the flipped classroom in nursing education. Nurse education today, 38, 15-21.

Cheng, K. H., \& Tsai, C. C. (2011). An investigation of Taiwan University students' perceptions of online academic help seeking, and their web-based learning self-efficacy. The Internet and Higher Education, 14, 150-157

Chu, H. C., Hwang, G. J., Tsai, C. C., \& Tseng, J. C. R. (2010). A two-tier test approach to developing location-aware mobile learning systems for natural science courses. Computers \& Education, 55(4), 1618-1627

Davies, R. S., Dean, D. L., \& Ball, N. (2013). Flipping the classroom and instructional technology integration in a college-level information systems spreadsheet course. Educational Technology Research and Development, 61(4), 563-580.

Day, J. A., \& Foley, J. D. (2006). Evaluating a web lecture intervention in a human-computer interaction course. IEEE Transactions on Education, 49(4), 420-431.

Flumerfelt, S., \& Green, G. (2013). Using lean in the flipped classroom for at risk students. Educational Technology and Society, 16(1), 356-366. 
Frey, A., Faul, A., \& Yankelov, P. (2003). Student perceptions of web-assisted teaching strategies. Journal of Social Work Education, 39(3), 443-457.

Fulton, K. P. (2012). 10 reasons to flip. Phi Delta Kappan, 94(2), 20-24

Jensen, J. L., Kummer, T. A., \& Godoy, P. D. D. M. (2015). Improvements from a flipped classroom may simply be the fruits of active learning. CBE -- Life Sciences Education, 14(1), 1-12.

Kay, R., \& Kletskin, I. (2012). Evaluating the use of problem-based video podcasts to teach mathematics in higher education. Computers $\mathcal{E}$ Education, 59(2), 619-627.

Kong, S. C. (2014). Developing information literacy and critical thinking skills through domain knowledge learning in digital classrooms: An experience of practicing flipped classroom strategy. Computers $\mathcal{E}$ Education, 78, 160-173.

Moraros, J., Islam, A., Yu, S., Banow, R., \& Schindelka, B. (2015). Flipping for success: Evaluating the effectiveness of a novel teaching approach in a graduate level setting. BMC Medical Education, 15(1), 27-27.

Nam, C. W., \& Zellner, R. D. (2011). The relative effects of positive interdependence and group processing on student achievement and attitude in online cooperative learning. Computers $\mathcal{E}$ Education, 56, 680-688.

O'Flaherty, J., \& Phillips, C. (2015). The use of flipped classrooms in higher education: A scoping review. The Internet and Higher Education, 25, 85-95.

Prinsen, F. R., Volman, M. L. L., Terwel, J., \& Van den Eeden, P. (2009). Effects on participation of an experimental CSCL-programme to support elaboration: Do all students benefit? Computers $\mathcal{E}$ Education, 52(1), 113-125.

Shea, P., \& Bidjerano, T. (2010). Learning presence: Towards a theory of self-efficacy, selfregulation, and the development of a communities of inquiry in online and blended learning environments. Computers $\mathcal{E}$ Education, 55(4), 1721-1731.

Wang, C. H., Shannon, D. M., \& Ross, M. E. (2013). Students' characteristics, self-regulated learning, technology self-efficacy, and course outcomes in online learning. Distance Education, 34(3), 302-323.

Wenger, E. (1998). Communities of practice: Learning, meaning, and identity. Cambridge, UK: Cambridge University Press.

Wong, T. H., Ip, E. J., Lopes, I., \& Rajagopalan, V. (2014). Pharmacy students' performance and perceptions in a flipped teaching pilot on cardiac arrhythmias. American journal of pharmaceutical education, 78(10), 1-5.

Wu, T. J., \& Tai, Y. N. 2016. Effects of multimedia information technology integrated multi-sensory instruction on students' learning motivation and outcome. EURASIA Journal of Mathematics, Science and Technology Education, 12(4), 1065-1074.

Yukselturk, E., \& Bulut, S. (2007). Predictors for student success in an online course. Journal of Educational Technology E Society, 10(2), 71-83.

Zakaria, E., Chin, L. C., \& Daud, M. Y. (2010). The effects of cooperative learning experience on eighth grade students' achievement and attitude toward science. Journal of Social Sciences, 6(2), 272-275.

\section{http://www.ejmste.com}

